\title{
A New BODIPY Derivative Bearing Piperazine Group
}

\author{
Xin Qi. Sook Kyung Kim. Eun Jin Jun. Li Xu, Sung-Jin Kim, and Juyoung Yoon"
}

\author{
Division of Nano Science and Department of Chemistry, Ewha Womans University, Seoul 120-750, Korea \\ "E-mail: jyoonajewha.ackr \\ Received July 19, 2007
}

\begin{abstract}
A new BODIPY derivative bearing piperazine group was synthesized and its fluorescent changes towards metal ions as well as $\mathrm{pH}$ are studied. The title compound displayed a moderate selectivity for $\mathrm{Hg}^{2}$ among the metal ions examined.
\end{abstract}

Key Words : Fluorescent chemosensor, BODIPY, $\mathrm{IIg}^{21}$ sensor

\section{Introduction}

Fluorescent chemosensors for ions appear to be particularly attractive due to the simplicity and high detection limit of the fluorescence.' Over the last few years, 4,4difluoro-4-bora-3a,4a-diaza-s-indacene (BODIPY) derivatives have been utilized as useful fluorophores because of their advantages, such as high excitation coefficients, high fluorescence quantum yields and high stability against light and chemical reactions. ${ }^{2}$ Recently, the fluorescent chemosensors based on the BODIPY have been applied as metal ion sensor, ${ }^{3} \mathrm{pH}$ sensor, ${ }^{4} \mathrm{NO}$ sensor, ${ }^{5}$ etc.

Mercury contamination through oceanic and volcanic emission, ${ }^{6}$ gold mining, or solid waste incineration has been an important issue because of its severe immunotoxic, genotoxic, and neurotoxic effects. Accordingly, considerable attention has been devoted to the development of new fluorescent chemosensors for the detection of $\mathrm{Hg}^{2+}$.

We report herein the synthesis and X-ray crystal structure of a new BODIPY derivative 1 bearing a piperazine group and its fluorescent changes towards metal jons as well as $\mathrm{pH}$. Compound 1 displayed a moderate fluorescent change with $\mathrm{Hg}^{2+}$ among the metal ions examined. Furthemore, the reversible protonation/deprotonation of 1 in aqueous solution was also studied.

\section{Results and Discussion}

4-(4-Methylpiperazin-1-y])benzaldehyde 3 and 2,4-dimethylpyrrole was reacted to give compound $\mathbf{1}$ as a red powder in $21 \%$ yield after flash chromatography $\mathrm{MC}$ : $\mathrm{MeOH}=50: 1)$ followed by a further separation via preparative $\mathrm{TLC}(\mathrm{MC}: \mathrm{MeOH}=50: 1, \mathrm{v} / \mathrm{v})$ (Scheme I). Compound 2 was synthesized by the reported procedure. ${ }^{9}$

In the X-ray structure of 1 (Figure I), the phenyl and pyrrole rings are planar, with an average deviation of 0.0019 and $0.0235 \AA$, respectively. The dihedral angle between the phenyl and pyrrolyl rings is $75.09^{\circ}$, which may be influenced by intramolecular interaction of hydrogen bonds (C1$\mathrm{H} 1 \mathrm{~A} \cdots \mathrm{F} 1$ and $\mathrm{Cl} 2-\mathrm{H} 12 \mathrm{C} \cdots \mathrm{F} 2, \mathrm{Cl}-\mathrm{H} 1 \mathrm{C} \cdots \mathrm{F} 2, \mathrm{Cl} 2-\mathrm{H} 12 \mathrm{~A}$
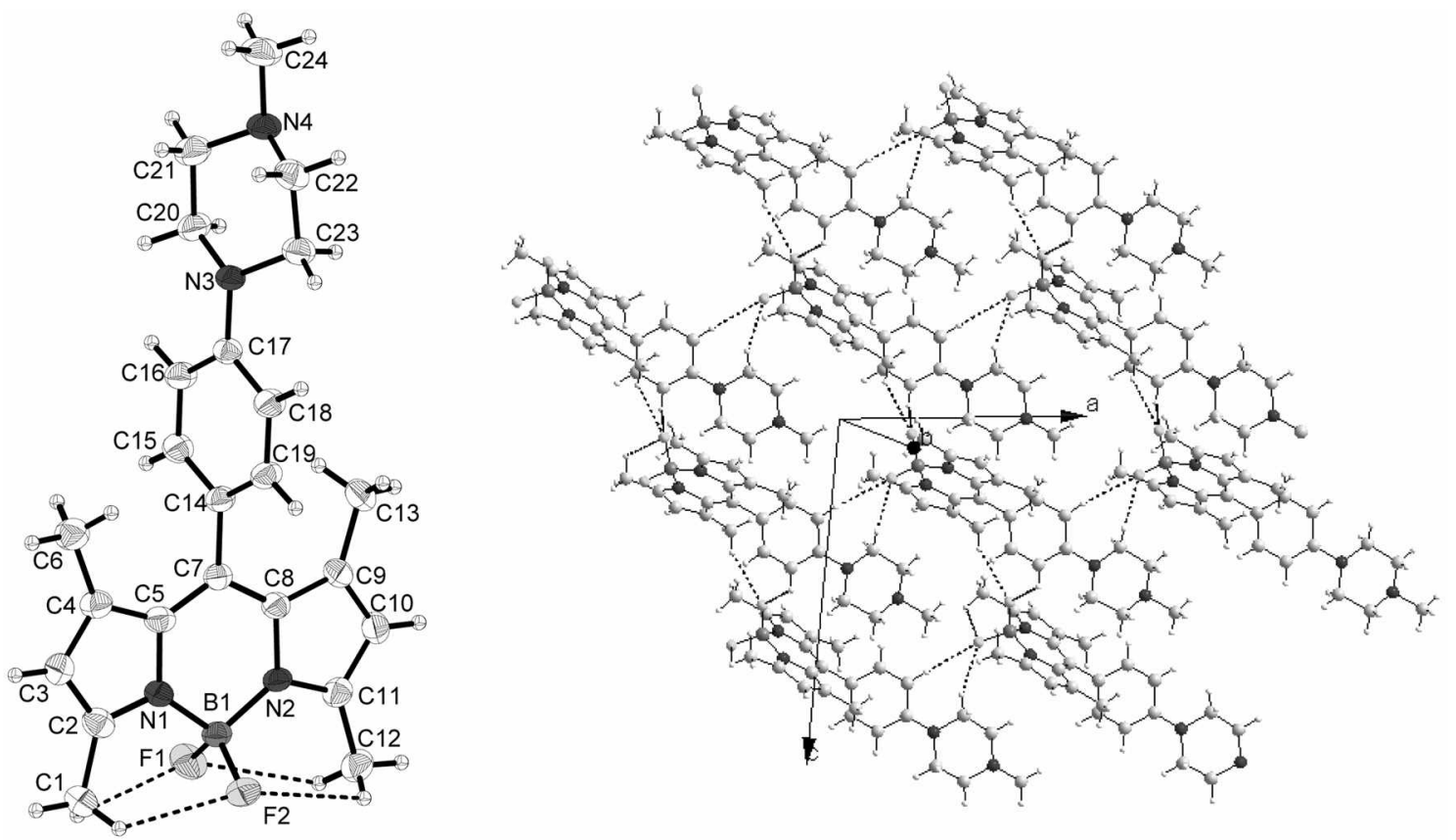

Figure 1. X-ray crystal structure of compound 1. 
<smiles>[R]c1ccc(C=O)cc1</smiles>
(i) 2,4-dimethylpyrrole, TFA, MC, rt, overnight (ii) DDQ, MC, $\mathrm{rt}, 4 \mathrm{~h}$

(iii) TEA, $\mathrm{BF}_{3} \mathrm{OEt}_{2}$, it, overnight

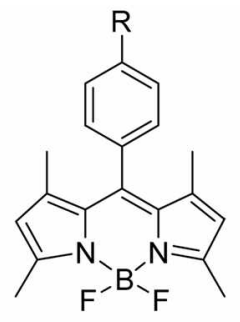<smiles>CN(C)C</smiles><smiles>CN1CCN([TeH4+])CC1</smiles>

2: $-\mathrm{N}_{\mathrm{CH}_{3}}^{\mathrm{CH}}$ $37 \%$

Scheme 1. Synthesis of compound 1 and 2.

...F2) between $\mathrm{F}$ atoms and methyl groups. By intermolecular hydrogen bonds (C16-H16 $\cdots \mathrm{F} 2, \mathrm{C} 20-\mathrm{H} 20 \mathrm{~A} \cdots \mathrm{F} 2$, C13-HI3A $\cdots \mathrm{FI}, \mathrm{C18}-\mathrm{HI}(\mathrm{FFI})$, the molecules of $\mathbf{1}$ are linked into a complex sheet (Figure 1).

$\mathrm{Ag}^{+}, \mathrm{Ca}^{2+}, \mathrm{Cd}^{2+}, \mathrm{Co}^{2+}, \mathrm{Cu}^{2+}, \mathrm{Cs}^{+}, \mathrm{Hg}^{2+}, \mathrm{K}^{+}, \mathrm{Mg}^{2+}, \mathrm{Mn}^{2+}$, $\mathrm{Na}^{+}, \mathrm{Ni}^{2+}, \mathrm{Pb}^{2+}$ and $\mathrm{Zn}^{2+}$ ions were used to evaluate the metal ion binding properties of $\mathbf{1}$. Fluorescent studies were conducted in acetonitrile-water $(95.5, \mathrm{v} / \mathrm{v})$ and using a $1 \mu \mathrm{M}$ concentration of compound. The fluorescence emission changes of 1 upon the addition of various metal ions ( 100 eq.) are illustrated in Figure 2. The fluorescence spectra were obtained by excitation into the BODIPY fluorophore at $495 \mathrm{~nm}$, and both the excitation and emission slits were 3 nm. As shown in Figure 2, compound 1 displayed a moderate fluorescent quenching effect with $\mathrm{Hg}^{2+}$ and a moderate fluorescent enhancement with $\mathrm{Zn}^{2+}$ among the metal ions examined. Compound $\mathbf{1}$ also displayed relatively small fluorescent enhancement upon the addition of $\mathrm{Pb}^{2+}$ and $\mathrm{Mn}^{2+}$. The fluorescent enhancements of compound 1 upon the addition of $\mathrm{Zn}^{2+}, \mathrm{Pb}^{2+}$ or $\mathrm{Mn}^{2+}$ can be explained by the blocking of the PET mechanism process from amine moiety. ${ }^{1 \mathrm{a}}$ On the other hand, if a quenching metal ion such as $\mathrm{Hg}^{2+}$ (via enhanced spin-orbital coupling) ${ }^{10}$ binds tightly to the

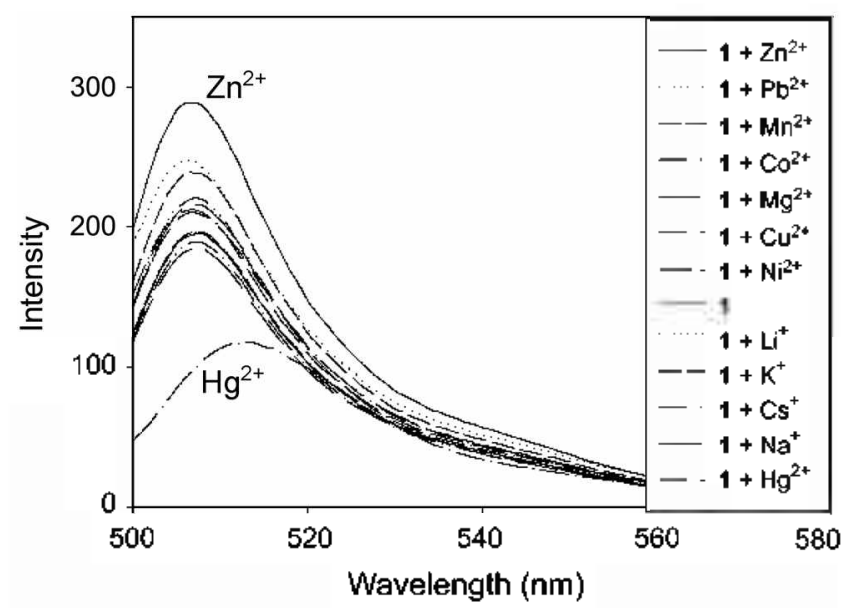

Figure 2. Fluorescence spectra of 1 ( $1 \mathrm{mM}$ ) upon the addition of various metal ions (perchlorate salts) in $\mathrm{CH}_{3} \mathrm{CN}$-water $(95: 5, \mathrm{v} / \mathrm{v})$ (cxcitation at $495 \mathrm{~nm}$ ). ligand, intracomplex quenching takes place.

From the fluorescence titration experiments, the association constants of 1 with $\mathrm{Hg}^{2+}$ (Figure 3) and $\mathrm{Zn}^{2+}$ were observed to be 2800 and $480 \mathrm{M}^{-1}$, respectively (errors < $10 \%) .^{11}$ The job plots using the fluorescence changes indicated $1: 1$ binding for 1 with $\mathrm{Hg}^{-1+}$ (Figure 4) and $\mathrm{Zn}^{2+}$.

Figure 5 displayed fluorescence emission spectra of 1 in aqueous nonbuffered solution (acetonitrile-water $=2: 8, \mathrm{v} / \mathrm{v}$ ) as a function of $\mathrm{pH}$. By lowering the $\mathrm{pH}$, fluorescence signal increase significantly. Wemer et al. reported that compound 2 displayed a similar fluorescent change according to $\mathrm{pH}$ in methanol-water mixture $(5: 5, v / v){ }^{9}$ The $\mathrm{p} K a$ value was reported as 3.3 in this solvent system. We repeated the same experiment in acetonitrile-water $(2: 8, \mathrm{v} / \mathrm{v})$ and a similar $\mathrm{pKa}$ value (3.5) was obtained. On the other hand, the $\mathrm{pKa}$ value of compound 1 was calculated as 1.8 from $\mathrm{pH}$ titration experiments (Figure 5). ${ }^{11}$ Virtually no dependence of absorption intensities versus $\mathrm{pH}$ was observed for both of these compounds (Figure 6). The pKa difference between these two compounds can be explained by the better electron releasing effect of a piperazine group compared to a dimethyl group.

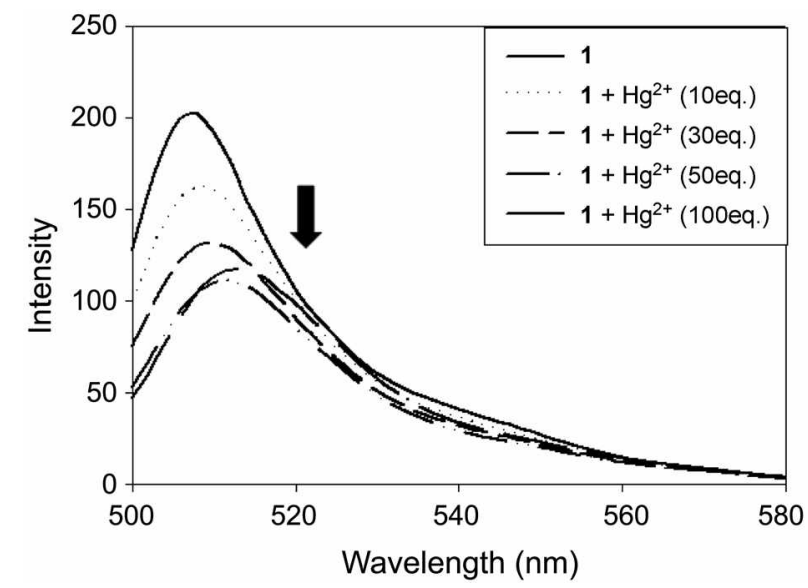

Figure 3. Fluorescence titrations of $1(1 \mu \mathrm{M})$ with $\mathrm{Hg}^{2+}$ in $\mathrm{CH}_{3} \mathrm{CN}$ water $(95: 5, \mathrm{v} / \mathrm{v})$ (excitation at $495 \mathrm{~nm}$ ).

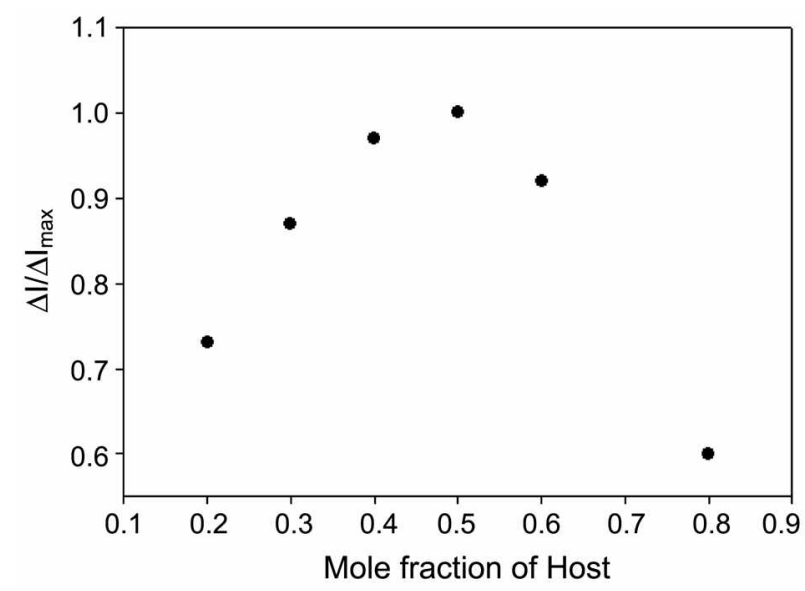

Figure 4. Job' plot between host 1 and $\mathrm{Hg}^{2+}$ using fluorescence crnission changes in $\mathrm{CH}_{3} \mathrm{CN}$-water $(2: 8, \mathrm{v} / \mathrm{v})$ (cxcitation at $495 \mathrm{~nm}$, cmission at $510 \mathrm{nun})$. 


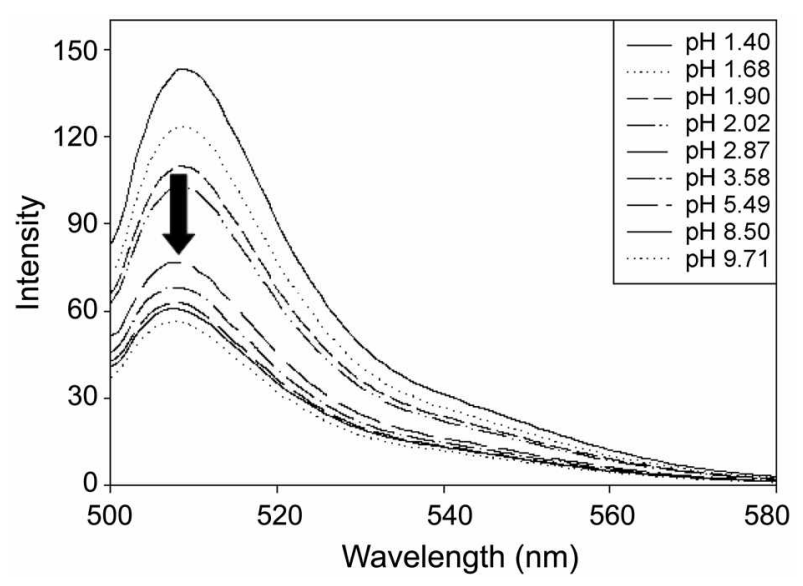

Figure 5. Fluorescence pH titrations of $1(1 \mu \mathrm{M})$ in $\mathrm{CH}_{3} \mathrm{CN}$-water $(2: 8, \mathrm{v} / \mathrm{v})($ excitation at $495 \mathrm{~nm})$.

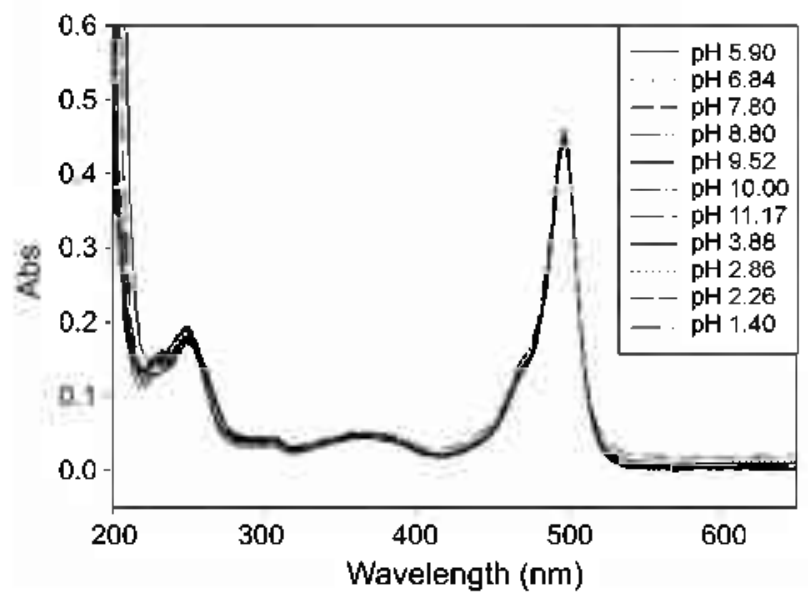

Figure 6. UV $\mathrm{pH}$ titrations of $1(15 \mu \mathrm{M})$ in $\mathrm{CH}_{3} \mathrm{CN}$-water $(2: 8, \mathrm{v} / \mathrm{v})$ (cxcitation at $495 \mathrm{~nm}$ ).

In conclusion, we synthesized a new BODIPY derivative bearing a piperazine group (1) and explained X-ray crystal structure of this compound. Compound $\mathbf{1}$ displayed a moderate selectivity for $\mathrm{Hg}^{2+}$ among the metal ions examined. The $\mathrm{pK}$ a value of this compound was productively compared to the aniline-type BODIPY (2).

\section{Experimental}

General methods. Unless otherwise noted, materials were obtained from commercial suppliers and were used without further purification. Flash chromatography was carried out on silica gel 60 (230-400 mesh ASTM; Merck). Thin layer chromatography (TLC) was carried out using Merck $60 \mathrm{~F}_{25+}$ plates with a thickness of $0.25 \mathrm{~mm}$. Preparative TLC was performed using Merck $60 \mathrm{~F}_{254}$ plates with a thickness of $\mathrm{I}$ $\mathrm{mm}$.

Melting points were measured using a Büchi 530 melting point apparatus, and are uncorrected. ${ }^{1} \mathrm{H}$ NMR and ${ }^{13} \mathrm{C} \mathrm{NMR}$ spectra were recorded using Bruker 500 . Chemical shifts were expressed in ppm, using TMS as an intemal standard. Mass spectra were obtained using a JMS-HX $110 \mathrm{~A} / 110 \mathrm{~A}$ Tandem Mass Spectrometer (JEOL).
Crystallographic data for the structure reported here have been deposited with the Cambridge Crystallographic Data Centre (Deposition No. CCDC-659972). That data can be obtained free of charge via http://www.ccdc.cam.ac.uk/perl/ catreq.cgi (or from the CCDC, 12 Union Road, Cambridge CB2 IEZ, UK; fax: +44 I223 336033; e-mail: deposit@ ccdc.cam.ac.uk)

4,4-Difluoro-8-[4-(4'-methylpiperazin-1'-yl)phenyl]1,3,5,7-tetramethyl-4-bora-3a,4a-diaza-s-indacene 1 . 4-(4-Methylpiperazin-I-yl)benzaldehyde 3 (204.3 mg, I mmol) and 2,4-dimethylpyrrole (190.3 $\mathrm{mg}, 2 \mathrm{mmol}$ ) was dissolved in anhydrous methylene chloride $(30 \mathrm{~mL})$ under argon atmosphere. Trifluoroacetic acid $(0.05 \mathrm{~mL})$ was added and the solution was stirred at room temperature ovenight. A solution of 2,3-dichloro-5,6-dicyano-1,4-benzoquinone $(227.0 \mathrm{mg}, 1 \mathrm{mmol})$ in anhydrous toluene $(30 \mathrm{~mL})$ was added by syringe and the stirring was continued for another 4h. After the addition of triethylamine $(6 \mathrm{~mL}), \mathrm{BF}_{3} \cdot \mathrm{OEt}_{2}(6$ $\mathrm{mL}$ ) was gradually added during $30 \mathrm{~min}$ in an ice-water bath followed by continuous stirring at room temperature overnight. The reaction solution was shaken with $10 \%$ aqueous sodium carbonate $(80 \mathrm{~mL})$ and the mixture was passed through a Celite pad and washed with $\mathrm{MC}(30 \mathrm{~mL})$ to remove the black solid. The organic layer was washed with water, dried over anhydrous sodium sulfate. After concentration in vacuo, the residue was purified by flash chromatography ( $\mathrm{MC}: \mathrm{MeOH}=50: 1$ ) followed by a further separation via preparative $\mathrm{TLC}(\mathrm{MC}: \mathrm{MeOH}=50: 1)$ procedure to afford a red powder $(89.6 \mathrm{mg}, 0.212 \mathrm{mmol}$, yield $21.2 \%)$. The analytical sample was recrystallized from ethyl acetate/ hexane to get a red crystal: $\mathrm{mp} 235^{\circ} \mathrm{C}$; 'H NMR $\left(\mathrm{CDCl}_{3}\right): \delta$ $1.46(\mathrm{~s}, 6 \mathrm{H}), 2.41(\mathrm{~s}, 3 \mathrm{H}), 2.55(\mathrm{~s}, 6 \mathrm{H}), 2.64(\mathrm{t}, 4 \mathrm{H}, J=4.8$ $\mathrm{Hz}), 3.29$ (t, $4 \mathrm{H}, J=4.9 \mathrm{~Hz}), 5.97(\mathrm{~s}, 2 \mathrm{H}), 6.99$ (d, $2 \mathrm{H}, J=$ $8.7 \mathrm{~Hz}), 7.10(\mathrm{~d}, 2 \mathrm{H}, J=8.6 \mathrm{~Hz}) .{ }^{13} \mathrm{C} \mathrm{NMR}\left(\mathrm{CDCl}_{3}\right): \delta 14.3$, $14.4,45.7,54.6,115.6,120.7,125.3,128.5,131.6,142.1$, $142.9,151.2,154.7$. HRMS: calcd. $\mathrm{M}^{+}$for $\mathrm{C}_{24} \mathrm{H}_{2} 9 \mathrm{BF}_{2} \mathrm{~N}_{4}$ 422.2453 , found. 422.2469 .

Acknowledgments. This work was supported by the SRC program of the Korea Science and Engineering Foundation (KOSEF) (RI1-2005-00000-0), the Basic Science Research of KOSEF (R01-2006-000-10001-0), the NRL program of KOSEF (R04-2007-000-2007-0), and BK21.

\section{References}

I. (a) de Silva, A. P.; Gunaratne, H. Q. N.; Gunnlaugsson, T. A.; Huxley, T. M.; McCoy, C. P.; Rademacher, J. T.; Rice, T. E. Chen. Rev. 1997, 97, 1515. (b) Martínez-Mânez, R.; Sancanón, F. Chem. Rev 2003, 103, 4419. (c) Callan, J. F.; de Silva, A. P.; Magri, D. C. Ietrahedron 2005, 61, 855I. (d) Yoon, J.; Kim, S. K.; Singh, N. J.; Kim, K. S. Chem. Soc, Rev, 2006, 35, 355. (e) Kim, S. K,; Kim, H. N.; Xiaon, Z.; Lee, H. N.; Lee, H. N.; Soh, J. H.; Swamy, K. M. K.; Yoon, J. Stipranolectiar Chen. 2007, 19, 221. (e) Kim, S. K.; Lee, J. H.; Yoon, J. Bull. Korean Chem. Soc. 2003, 24, 1032.

2. Haugland, R. P. Handbook of Fhorescent Probes and Research Chemicals, 91h ed.; Molecular Probes Inc.: Eugene, Oregon, 2002.

3. (a) Turfan, B.; Akkaya, E. U. Org. Lett. 2002, 4, 2857. (b) Goze, C.; Ulrich, G; Charbonniêre, L.; Cesario, M.; Prangê, T.; Ziessel, 
R. Chem. Eur. J. 2003, 9, 3748. (c) Moon, S. Y.; Cha, N. R.; Kim, Y. H.; Chang. S.-K. J. Org. Chem. 2004, 69, 181 . (d) Yamada. K.; Nomura, Y.; Citterio, D.; Jwasawa, N.; Suzuki, K. J. Am. Chem. Soc. 2005, 127, 6956. (e) Coskun, A.; Akkaya, E. U. J. Am. Chem. Soc. 2005, 127, 10464. ( () Qi, X.; Jun, E. J.; Xu, L.; Kim, S.-J.; Hong, J. S. J.; Yoon, Y. J.; Yoon, J. J. Org. Chem. 2006, 7l, 2881. (g) Yu, Y.-H.; Descalzo, A. B.; Shen, Z.; Röhr, H.; Liu, Q.; Wang, Y.-W.; Spieles, M.; Li, Y.-Z.; Rurack, K.; You, X.-Z. Chem. Asian J. 2006, 1-2, 176. (h) Coskun. A.; Akkaya, E. U. J. Am. Chem. Soc, 2006, 128, 14474. (i) Peng, X.; Du, J.; Fan, J.; Wang, J.; Wu, Y.; Zhao, J.; Sun, S.; Xu, T. J. Am. Chem. Soc. 2007, 129, 1500.

4. Baruah, M.; Qin, W.; Basaria, N.; De Borggaeve, W. M.; Boens, N. J. Org. Chem. 2005, 70,4152.

5. Gabe, Y.; Urano, Y.; Kikuchi, K.; Kojima, H.; Nagano, T. J. Ant. Chem. Soc. 2004, I26, 3357.

6. Renzoni, A.; Zino, F.; Franchi, E. Emiron, Res, 1998, 77, 68.

7. Malm, O. Environ. Res, $1998,77,7$

8. (a) Soh, J. H.; Swamy, K. M. K.; Kim, S. K.; Kim, S.; Lee, S.-H.; Yoon, J. Tetrahedron Lett. 2007, 48, 5966. (b) Kim, S. H.; Kim. J.
S.; Park, S. M.; Chang, S.-K. Org. Left. 2006, 8, 371. (c) Yoon, S.; Albers, A. E.; Wong, A. P.; Chang, C. J. J. Am. Chem. Soc. 2005 , 127, 16030. (d) Moon, S.-Y.; Youn, N. J.; Park, S. M.; Chang, S.K. J. Org. Chem. 2005, 70, 2394. (e) Martinez, R.; Espinosa, A.; Tárraga, A.; Molina, P. Org. Lett. 2005, 7, 5869. (f) Matsushita, M.; Meijler, M. M.; Wirsching, P.; Lerner, R.; Janda, K. D. Org. Lett. 2005, 7, 4943. (g) Moon, S. Y.; Cha, N. R.; Kim, Y. H.; Chang. S.-K. J. Org. Chem. 2004, 69, I8I. (h) Kwon, J. Y.; Soh, J. H.; Yoon, Y. J.; Yoon, J. Supramolectlar Chem. 2004, 16. 621. (i) Guo, X.; Qian, X.; Jia, L. J. Am. Chem. Soc. 2004, J26, 2272. (j) Nolan, E. M.; Lippard, S. J. J. Am. Chem. Soc. 2003, 125, 14270.

9. Werner, T.; Huber, C.; Heinl, S.; Kollmannsberger, M.; Daub, J.; Wolfbeis, O. S. Fresentits J. Anal. Chem. 1997, 359, 150.

10. McClure, D. S. J. Chent. Phys. 1952, 20,682.

11. (a) Association constants were obtained using the computer program ENZFITTER, available from Elsevier-BIOSOFT, 68 Hills Road, Cambridge CB2 ILA, United Kingdom. (b) Conners, K. A. Binding Constants, The Measurement of Molecilar Complex Stability; Wiley: New York, 1987. 